Military Technical College

Kobry Elkobbah,

Cairo, Egypt

May 25-27,2010

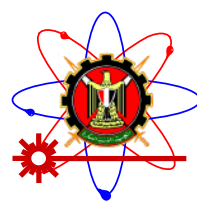

$5^{\text {th }}$ International Conference on Mathematics and Engineering Physics (ICMEP-5)

\title{
EM-10
}

\section{EVALUATING WEAPONS SYSTEM USING FUZZY APPROXIMATE REASONING}

\author{
Mahmod Othman, Ku Ruhana Ku-Mahamud, Mohamad Fadhili Yahaya
}

\begin{abstract}
:
This paper proposed the application of the fuzzy evaluation model using fuzzy sets and approximate reasoning. The objective of the study is to evaluate the weapon system in a subjective environment. The proposed method based on fuzzy sets has initiated the idea of membership set score value evaluation of each criterion alternative. This enables the inclusion of requirements which are incomplete and imprecise. The approximate reasoning of the method allows the decision maker to make the best choice in accordance to human thinking and reasoning processes. The proposed model is based on fuzzy multi-criteria decisionmaking that consists of fuzzy rules. The use of fuzzy rules, which are extracted directly from input data in making evaluation, contributes to a better decision in selecting the best option and less dependency on the domain of experts. Finally, we constructed a practical example for evaluating attack helicopters to demonstrate the proposed method. From these results, the proposed method shows outstanding performance in comparing with Cheng et al.'s method with $100 \%$ accuracy in ranking three attack helicopter alternatives, S1 (MI-28), S2 (AH-64, and S3 (AH-1w). Again the subjective evaluation method showed the advantages of simpler rules properties in NR, Max_L and Min_L. This research work has achieved its objective and produced good evaluation results. This portrays its major advantages in making decisions in new cases, where there is limited or an absence of specific knowledge.

Keywords: Fuzzy sets, Multi-criteria decision making, approximate reasoning.
\end{abstract}

\section{INTRODUCTION}

In making good decision, a highly reliable evaluation method is crucial. Such evaluation normally conducted using subjective criteria requires one to use his or her wisdom, experience, professional knowledge and information, which is difficult to define or describe precisely. When analysing using incomplete data, a lot of uncertainties will arise this will confuse decision-makers and will complicate decision-making as it is made under unknown situations. The application of fuzzy sets theory in evaluation systems can improve the evaluation results (Turban, et al. 2000). Several researchers have tried to solve this problem through analytical hierarchy process (AHP), for example in personnel selection (Liang \& Wang, 1992; Sonja, 2001) and shipping performance evaluation (Chou \& Liang, 2001), whereby evaluation was done by aggregating all the fuzzy sets. However, the presence of 
imprecision, vagueness and subjectivity at each level further accumulates greatly the undesired elements in aggregating the marks.

In the literature, various concepts have been proposed focusing on the combination of fuzzy logic model with multi objective decision that can assist in reducing errors in deriving to a judgment (Pedrycz \& Gomide, 1982; Liang \& Wang, 1992). The research provides approaches to judgment procedure on personnel selection through the development of AHP fuzzy multi criteria. It is cited as being able to minimise subjectivity. Some research in fuzzy evaluation methods is discussed in Othman (2004a; 2004b; 2004c). The authors have proposed algorithms based either on fuzzy similarity function or fuzzy synthetic decision and ranking procedure through satisfaction function. Fuzzy sets membership enables the interpretations of linguistic variables in a very natural and plausible way to formulate and solve various problems. However, expressing the linguistic variable using the singleton fuzzy sets such as in Capaldo and Weon (2001) could result in the loss of much important information and would additionally complicate the course of action. Although many evaluation methods for selecting or ranking have been suggested in the literature, there is yet a method which can give a satisfactory solution to every situation. For this reason, a fuzzy evaluation method is proposed by combining the concepts introduced by Othman (2003) and integrating it with a fuzzy rule (Othman, 2004a) that is derived automatically from input data. This research makes its contribution by introducing the bridging and linking of these two methods. Previous studies on fuzzy evaluation methods evaluate (Tseng \& Yeh, 2000; Chang \& Yeh, 2002; and Kuo \& Chen, 2002) the use of the number of respondents who answered the survey questions to represent fuzzy set in the forms of membership function. However, these methods have a drawback, whereby they are unable to produce a generalised fuzzy evaluation method to evaluate various types of data. Hence, this research introduced the membership set score where various input data are transformed and are not predetermined by the expert. This is important to ensure the consistency in generalising the proposed framework.

The paper proceeds as follows. The proposed model is introduced in Section 2. Section 4 presents the algorithm of the proposed model and numerical results. It is followed by the concluding in Section 5.

\subsection{Case Background}

Data on the evaluation attack helicopters based on linguistic variable (Cheng et al., 1999) has been used. The five criteria for the best attack helicopter namely technological advance, logistic capability, armament, avionics, and subsisting ability. Three alternatives labeled as S1 (MI-28), S2 (AH-64, and S3 (AH-1w) are used to decide entities of the attack helicopters. Table 1 depicted the data of technology advances for three attack helicopters and their judgement criteria. This table contained the original data of performance scores given by the expert's opinion on particular subcriteria. From these scores the membership functions are constructed and tabulated in the last column of the table. Linguistic terms are found to be easy to express the subjective and imprecise assessments (Yeh et al., 2000). The membership functions are characterized by the triangular fuzzy number defined as triplet $\left(a_{1}, a_{2}, a_{3}\right)$. The triangular fuzzy numbers are the average performance rating values in range of $a_{1}$ and $a_{3}$. The membership function is defined as

$$
\mu_{\mathrm{A}}(x)=\left\{\begin{array}{cl}
0 & \\
\frac{x_{i}-\iota}{T-a}, & a_{1} \leq x_{i} \leq T \\
1, & x_{i} \geq T
\end{array}\right.
$$

where, $x_{i}$ is fuzzy evaluation of alternative in torm of triangular fuzzy number, $T$ is the vertex of the triangular fuzzy number and $a_{1}$ and $a^{x_{i} \leq a_{1}}$ two endpoints. 
Table 1: data of technology advances for three attack helicopters

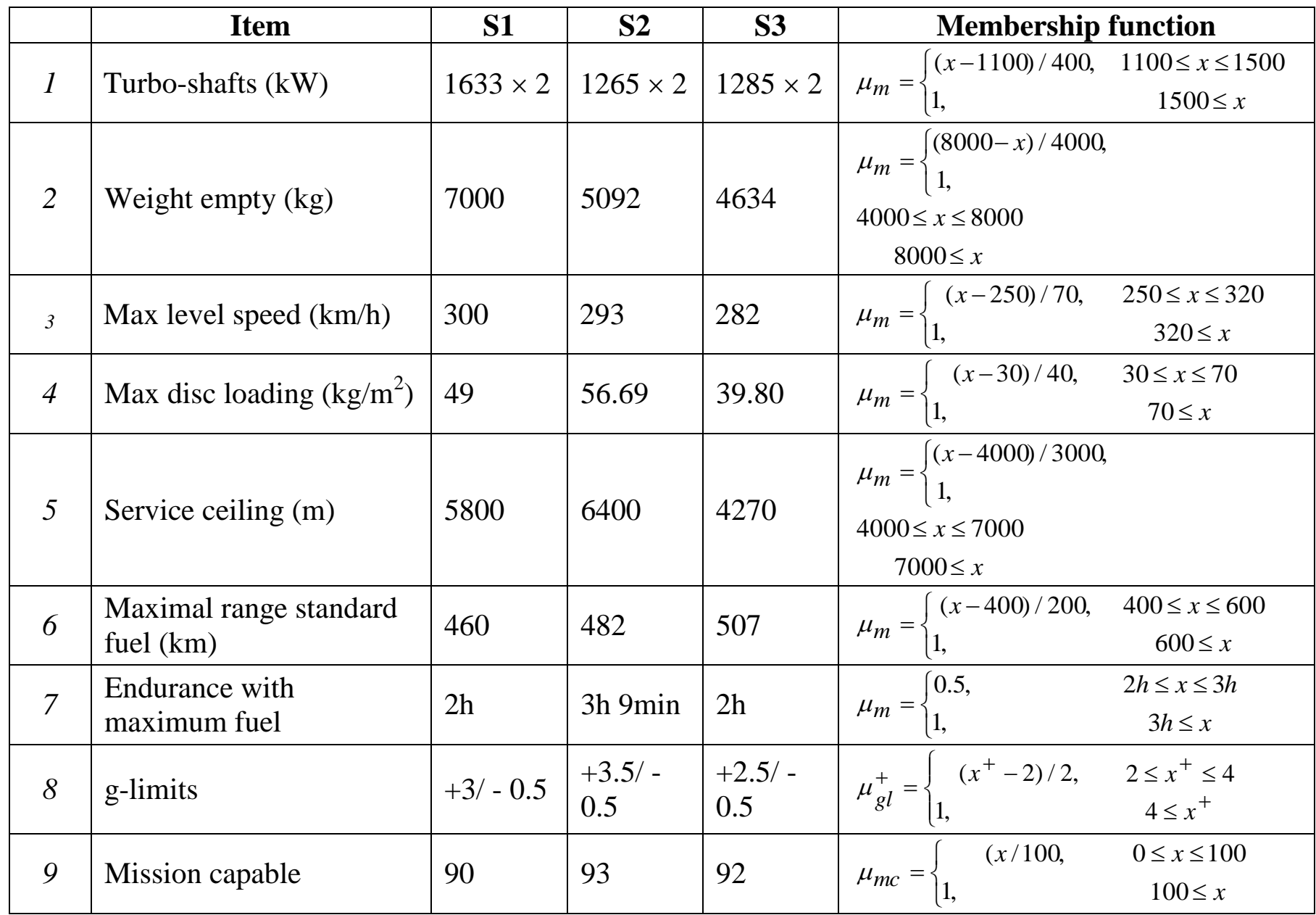

The performance scores in the form of fuzzy sets are calculated using the Equation 1 and tabulated in table 2. The total performance scores of the three alternatives S1, S2, and S3 are shown in the last row of Table 2.

Table 2: The scores of technological advances derived from Table 1

\begin{tabular}{|l|l|l|l|l|}
\hline & \multicolumn{1}{|c|}{ Item } & \multicolumn{1}{c|}{ S1 } & \multicolumn{1}{c|}{ S2 } & \multicolumn{1}{c|}{ S3 } \\
\hline 1 & Turbo-shafts $(\mathrm{kW})$ & 1 & 0.41 & 0.46 \\
\hline 2 & Weight empty $(\mathrm{kg})$ & 0.25 & 0.72 & 0.84 \\
\hline 3 & Max level speed $(\mathrm{km} / \mathrm{h})$ & 0.71 & 0.61 & 0.46 \\
\hline 4 & Max disc loading $\left(\mathrm{kg} / \mathrm{m}^{2}\right)$ & 0.49 & 0.67 & 0.25 \\
\hline 5 & Service ceiling $(\mathrm{m})$ & 0.6 & 0.8 & 0.09 \\
\hline 6 & $\begin{array}{l}\text { Maximal range standard } \\
\text { fuel }(\mathrm{km})\end{array}$ & 0.3 & 0.41 & 0.54 \\
\hline 7 & $\begin{array}{l}\text { Endurance with } \\
\text { maximum fuel }\end{array}$ & 0.5 & 1 & 0.5 \\
\hline 8 & g-limits & 0.5 & 1 & 0.25 \\
\hline 9 & Mission capable & 0.9 & 0.93 & 0.92 \\
\hline & Total & $\mathbf{5 . 2 5}$ & $\mathbf{6 . 5 5}$ & $\mathbf{4 . 3 1}$ \\
\hline
\end{tabular}

Next, Some of the evaluations given by an expert are in the form of linguistic terms. The linguistic terms with the corresponding membership function as defined in Figure 1 are used to facilitate the subjective assessment in evaluating the weapon systems. 


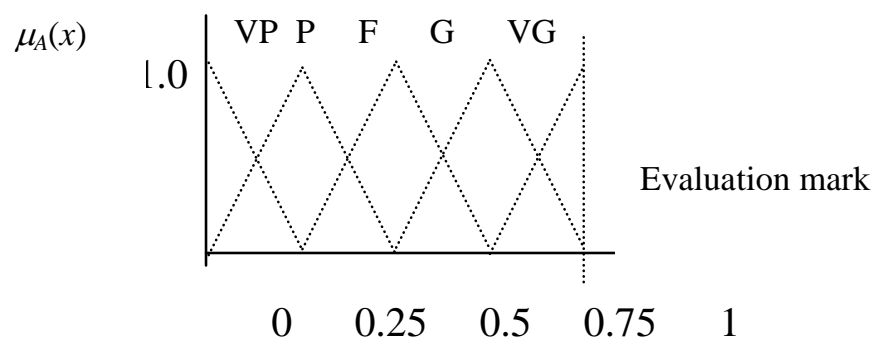

Figure 1. Membership Functions of Linguistic Terms

Then, from this term the scores for the criteria are allocated by taking an appropriate mean of fuzzy number as tabulated in Table 2 .

Table 2: Linguistic value

\begin{tabular}{|l|l|}
\hline \multicolumn{1}{|c|}{ Fuzzy language } & \multicolumn{1}{|c|}{$\begin{array}{c}\text { The mean of fuzzy } \\
\text { number }\end{array}$} \\
\hline Very good & 1 \\
\hline Good & 0.75 \\
\hline Fair & 0.5 \\
\hline Poor & 0.25 \\
\hline Very poor & 0 \\
\hline
\end{tabular}

Table 3 depicted the original data of performance scores given by the expert's opinion on particular subcriteria in the form of linguistic evaluation.

Table 3: Linguistic Logistic capability evaluation

\begin{tabular}{|c|l|l|l|l|}
\hline & \multicolumn{1}{|c|}{ Item } & \multicolumn{1}{c|}{ S1 } & \multicolumn{1}{c|}{ S2 } & \multicolumn{1}{c|}{ S3 } \\
\hline 1 & Reliability & Fair & Good & Good \\
\hline 2 & Maintenance ability & $\begin{array}{l}\text { Very } \\
\text { Good }\end{array}$ & Good & Good \\
\hline 3 & Convey & Fair & $\begin{array}{l}\text { Very } \\
\text { Good }\end{array}$ & Good \\
\hline 4 & Economics & $\begin{array}{l}\text { Very } \\
\text { good }\end{array}$ & Good & $\begin{array}{l}\text { Very } \\
\text { Good }\end{array}$ \\
\hline 5 & $\begin{array}{l}\text { Flexibility for selecting } \\
\text { weapon }\end{array}$ & Good & $\begin{array}{l}\text { Very } \\
\text { Good }\end{array}$ & Good \\
\hline
\end{tabular}

Using an appropriate mean of fuzzy number in Table 2, the linguistic terms are translated as in Table 4.

Table 4: The Score of Logistic capability evaluation

\begin{tabular}{|l|l|l|l|l|}
\hline & \multicolumn{1}{|c|}{ Item } & \multicolumn{1}{c|}{ S1 } & \multicolumn{1}{c|}{ S2 } & \multicolumn{1}{c|}{ S3 } \\
\hline 1 & Reliability & 0.5 & 0.75 & 0.75 \\
\hline 2 & Maintenance ability & 1 & 0.75 & 0.75 \\
\hline 3 & Convey & Fair & 1 & 0.75 \\
\hline 4 & Economics & 1 & 0.75 & 1 \\
\hline
\end{tabular}




\begin{tabular}{|l|l|l|l|l|}
\hline 5 & $\begin{array}{l}\text { Flexibility for selecting } \\
\text { weapon }\end{array}$ & 0.75 & 1 & 0.75 \\
\hline
\end{tabular}

The data of armament which comprised of sub-factors: Guns, anti-tank, missiles, and rockets are tabulated in Table 5. The performance scores of the sub-factors of armament for three attack helicopters are calculated and shown in Table 6.

Table 5: The data of armament for three attack helicopters

\begin{tabular}{|c|c|c|c|c|c|}
\hline Item & & S1 & $\mathbf{S 2}$ & S3 & Membership function \\
\hline \multirow[t]{3}{*}{ Gun } & $\begin{array}{l}\text { Caliber }(\mathrm{mm}) \\
\text { Feed }\end{array}$ & 30 & 30 & 20 & $\mu_{m}=\left\{\begin{array}{cc}0.5, & 20 \leq x \leq 30 \\
1, & 30=x\end{array}\right.$ \\
\hline & $\begin{array}{l}\text { Firing rate } \\
(\mathrm{r} / \mathrm{m})\end{array}$ & 900 & 625 & 650 & $\mu_{f r}=\left\{\begin{array}{lc}(x-500) / 500, & 500 \leq x \leq 1000 \\
1, & 1000 \leq x\end{array}\right.$ \\
\hline & Feed & 300 & 1200 & 750 & $\mu_{g f}=\left\{\begin{array}{lc}(x-200) / 1000, & 200 \leq x \leq 1200 \\
1, & 1200 \leq x\end{array}\right.$ \\
\hline \multirow[t]{3}{*}{$\begin{array}{l}\text { Anti-tank } \\
\text { Missiles }\end{array}$} & Feed & 16 & 5092 & 4634 & $\mu_{a f}=\left\{\begin{array}{cc}x / 16, & 0 \leq x \leq 16 \\
1, & 16 \leq x\end{array}\right.$ \\
\hline & $\begin{array}{l}\text { Firing range } \\
(\mathrm{km})\end{array}$ & 5 & 8 & 8 & $\mu_{a t}=\left\{\begin{array}{cc}x / 10, & 0 \leq x \leq 10 \\
1, & 10 \leq x\end{array}\right.$ \\
\hline & $\begin{array}{l}\text { Firing } \\
\text { accuracy }(\%)\end{array}$ & 80 & 76 & 87 & $\mu_{a a}=\left\{\begin{array}{cc}x / 100, & 0 \leq x \leq 100 \\
1, & 100 \leq x\end{array}\right.$ \\
\hline \multirow[t]{2}{*}{$\begin{array}{l}\text { Air-to-air } \\
\text { missiles }\end{array}$} & Feed & 8 & 4 & 4 & $\mu_{a t}=\left\{\begin{array}{cc}x / 10, & 0 \leq x \leq 10 \\
1, & 10 \leq x\end{array}\right.$ \\
\hline & $\begin{array}{l}\text { Firing } \\
\text { accuracy }(\%)\end{array}$ & 85 & 90 & 50 & $\mu_{i a}=\left\{\begin{array}{cc}x / 100, & 0 \leq x \leq 100 \\
1, & 100 \leq x\end{array}\right.$ \\
\hline \multirow[t]{2}{*}{ Rocket } & Feed & $\begin{array}{l}20 \\
\times 4\end{array}$ & $19 \times 4$ & $19 \times 4$ & $\mu_{r f}=\left\{\begin{array}{cc}x / 100, & 0 \leq x \leq 100 \\
1, & 100 \leq x\end{array}\right.$ \\
\hline & Caliber $(\mathrm{mm})$ & 70 & 70 & 70 & $\mu_{r f}=\left\{\begin{array}{cc}x / 100, & 0 \leq x \leq 100 \\
1, & 100 \leq x\end{array}\right.$ \\
\hline
\end{tabular}

Table 6: The Scores of armament for three attack helicopters

\begin{tabular}{|c|l|l|l|l|}
\hline Item & \multicolumn{1}{|c|}{ Item } & \multicolumn{1}{c|}{ S1 } & \multicolumn{1}{c|}{ S2 } & \multicolumn{1}{c|}{ S3 } \\
\hline Gun & Caliber $(\mathrm{mm})$ & 1 & & 0.5 \\
& Firing rate $(\mathrm{r} / \mathrm{m})$ & 0.8 & 0.25 & 0.3 \\
& Feed & 0.1 & 1 & 0.75 \\
\hline & Feed & 1 & 1 & 0.75 \\
Anti-tank & Firing range $(\mathrm{km})$ & 0.5 & 0.8 & 0.8 \\
Missiles & Firing accuracy $(\%)$ & 0.8 & 0.76 & 0.87 \\
& & & & \\
\hline Air-to-air & Feed & 0.8 & 0.4 & 0.4 \\
missiles & Firing accuracy $(\%)$ & 0.85 & 0.9 & 0.5 \\
\hline Rocket & Feed & 0.8 & 0.76 & 0.76 \\
& Caliber $(\mathrm{mm})$ & 0.7 & 0.7 & 0.7 \\
\hline Total & & 7.35 & 7.57 & 6.08 \\
\hline
\end{tabular}


Lastly, the scores of the other criteria to select the best weapon that are Avionics, and Subsist ability are displayed in Table 7 and Table 8.

Table 7: The Scores of Avionics

\begin{tabular}{|c|l|l|l|l|}
\hline & \multicolumn{1}{|c|}{ Item } & \multicolumn{1}{|c|}{ S1 } & \multicolumn{1}{|c|}{ S2 } & \multicolumn{1}{|c|}{ S3 } \\
\hline 1 & Pilot night vision system & 0.5 & 1 & 0.25 \\
\hline 2 & $\begin{array}{l}\text { Target acquisition and } \\
\text { designation system }\end{array}$ & 0.5 & 1 & 0.5 \\
\hline 3 & Integrate system positioning & 0.25 & 1 & 0.5 \\
\hline 4 & $\begin{array}{l}\text { Global } \\
\text { system a pal }\end{array}$ & 1.75 & 0.5 \\
\hline & Total & $\mathbf{1 . 7 5}$ & $\mathbf{1 . 7 5}$ \\
\hline
\end{tabular}

Table 7: The Scores of Subsist Ability

\begin{tabular}{|l|l|l|l|l|}
\hline & \multicolumn{1}{|c|}{ Item } & \multicolumn{1}{c|}{ S1 } & \multicolumn{1}{c|}{ S2 } & \multicolumn{1}{c|}{ S3 } \\
\hline 1 & Amor-protection & 0.75 & 0.75 & 0.75 \\
\hline 2 & Counter-detected & 0.75 & 1 & 0.5 \\
\hline 3 & Pilot-protested & 1 & 0.75 & 0.5 \\
\hline 4 & Noise & 1 & 1 & 0.5 \\
\hline 5 & NBS protection & 1 & 0.5 & 0.5 \\
\hline & Total & $\mathbf{1 . 7 5}$ & $\mathbf{4}$ & $\mathbf{2 . 7 5}$ \\
\hline
\end{tabular}

In this research, the synthetic decision $r_{i j}$, which is single-criterion evaluation equivalent to $B_{i j}$.

$$
r_{i j}=B_{i j}
$$

where, $B_{i j}$ is a fuzzy subset in $\mathrm{P}$; it can also be represented by a fuzzy vector,

$$
B_{i j} \in M_{1 \times J}
$$

In ensuring the total score remains in the range $[0,1]$ the normalisation concept in Weon and Kim (2001) was adopted. The total of fuzzy marks of each criterion are used as input to develop the normalised synthetic score value. This is the seventh step of the subjective evaluation method. The calculation of normalised synthetic score value was based on the aggregation of multiplication score mark of each criterion and weight. The normalised synthetic score value is then calculated using Equation (4).

$$
\text { Normalised synthetic score }=\frac{1}{N} r_{m i}
$$

where $N$ is the number of criteria in each factor.

\section{THE FUZZY EVALUATION MODEL}

The algorithm for the evaluation model consists of 4 steps as listed below:

\begin{tabular}{|l|l|l|}
\hline Step 1 & $:$ & Calculate the normalised synthetic score value \\
\hline
\end{tabular}




\begin{tabular}{|l|l|l|}
\hline Step 2 & $:$ & $\begin{array}{l}\text { Determine multi-criteria rules combination and calculate factor rule } \\
\text { value }\end{array}$ \\
\hline Step 3 & $:$ & Calculate appraisal fuzzy value and the appraisal product value \\
\hline Step 4 & $:$ & Compute satisfaction value and ranking \\
\hline
\end{tabular}

There are 4 steps in the proposed model for evaluating the best attack helicopters. The first step is to transform the input data into normalised synthetic score value. The proposed model then constructs the normalized synthetic score value as shown in Table 7. Each element in the table is calculated by using Equation (4), the total score of each criterion.

Table 7: Normalised Synthetic Score Value

\begin{tabular}{|l|c|c|c|c|c|}
\hline \multirow{2}{*}{$\begin{array}{l}\text { Weapon } \\
\text { Systems }\end{array}$} & \multicolumn{5}{|c|}{ Criteria } \\
\cline { 2 - 6 } & $\mathrm{X}_{1}$ & $\mathrm{X}_{2}$ & $\mathrm{X}_{3}$ & $\mathrm{X}_{4}$ & $\mathrm{X}_{5}$ \\
\hline S1 & 0.332 & 0.313 & 0.350 & 0.233 & 0.400 \\
\hline S2 & 0.395 & 0.354 & 0.360 & 0.533 & 0.356 \\
\hline S3 & 0.273 & 0.333 & 0.290 & 0.233 & 0.244 \\
\hline
\end{tabular}

Table 8 shows the fuzzy rules generated by the proposed model from the weapons system data in terms of rules properties, number of rules, maximum length, minimum length are 3,3 and 3 respectively.

Table 8: Multi-criteria Rules Combination

\begin{tabular}{|c|c|c|c|c|}
\hline $\begin{array}{c}\text { Decision } \\
\text { Criteria }\end{array}$ & Factor Rule & $\begin{array}{c}\text { Linguistic } \\
\text { Variable }\end{array}$ & Description & Appraisal Set \\
\hline $\boldsymbol{C}_{\mathbf{1}}$ & $C_{2} \cap\left(C_{3} \cup C_{4}\right)$ & $A_{1}$ & Satisfactory & $v$ \\
\hline $\boldsymbol{C}_{\mathbf{2}}$ & $C_{3} \cap\left(C_{2} \cup C_{4}\right)$ & $A_{1}$ & Satisfactory & $v$ \\
\hline $\boldsymbol{C}_{\mathbf{3}}$ & $C_{4} \cap\left(C_{2} \cup C_{3}\right)$ & $A_{1}$ & Satisfactory & $v$ \\
\hline
\end{tabular}

Table 9: Factor Rule Value

\begin{tabular}{|l|c|c|c|}
\hline & $\boldsymbol{C}_{\mathbf{1}}$ & $\boldsymbol{C}_{\mathbf{2}}$ & $\boldsymbol{C}_{\mathbf{3}}$ \\
\hline S1 & 0.313 & 0.313 & 0.233 \\
\hline S2 & 0.354 & 0.360 & 0.360 \\
\hline S3 & 0.290 & 0.290 & 0.233 \\
\hline
\end{tabular}

Then the appraisal fuzzy value, $\left(d_{j}(m, l)\right)$, of Table 10 is computed as follows (Othman et al., 2004d):

$$
d_{j}(m, l)=1 \wedge\left(1-\tilde{c}\left(u_{m}\right)+A_{k}\left(v_{l}\right)\right)
$$

where $\mathrm{j}=1,2,3, \mathrm{~m}=1,2,3,1=1,2, \ldots, 11$ and $\tilde{c}\left(u_{m}\right)$ is the factor rule value. The appraisal fuzzy values for decision criteria $\mathrm{DC}_{1}$ is tabulated in Table 10. 
Table 10: Appraisal Fuzzy Value for Decision Criteria DC

\begin{tabular}{|c|c|c|c|c|c|c|c|c|c|c|c|}
\hline & \multicolumn{11}{|c|}{ Appraisal Set } \\
\hline \multirow{2}{*}{ S1 } & 0.687 & 0.700 & 0.800 & 0.900 & 1.000 & 1.000 & 1.000 & 1.000 & 1.000 & 1.000 & 1.000 \\
\hline & 0 & 0 & 0 & 0 & 0 & 0 & 0 & 0 & 0 & 0 & 0 \\
\hline \multirow{2}{*}{$\mathrm{S} 2$} & 0.400 & 0.500 & 0.600 & 0.700 & 0.800 & 0.900 & 1.000 & 1.000 & 1.000 & 1.000 & 1.000 \\
\hline & 0 & 0 & 0 & 0 & 0 & 0 & 0 & 0 & 0 & 0 & 0 \\
\hline \multirow{2}{*}{ S3 } & 0.650 & 0.750 & 0.850 & 0.950 & 1.000 & 1.000 & 1.000 & 1.000 & 1.000 & 1.000 & 1.000 \\
\hline & 0 & 0 & 0 & 0 & 0 & 0 & 0 & 0 & 0 & 0 & 0 \\
\hline
\end{tabular}

Therefore, the appraisal product value $\mathrm{D}$ is calculated by multiplying all the elements of the appraisal fuzzy value, $D_{j}$ obtained earlier. The formula is given in Equation 6 .

$$
\mathrm{D}=\left(\prod_{j=1}^{J} d_{j}(n, l)\right)=\left(\tilde{E}_{1}, \tilde{E}_{2}, \ldots, \tilde{E}_{F}, \ldots, \tilde{E}_{L}\right) \in M_{L \times 1}
$$

Assuming that $E_{m \alpha}$ is the $\alpha$ level of $\tilde{E}_{n}, \alpha \in[0,1]=\mathrm{I}$, it should be noted that the sets $E_{m \alpha}$ are ordinary subsets of $V$. Each $E_{m \alpha}, H_{l}\left(E_{m \alpha}\right)=$ mid-point is calculated. The calculated appraisal product value is shown in Table 11.

Table 11: Appraisal Product Value

\begin{tabular}{|c|c|c|c|c|c|c|c|c|c|c|c|}
\hline & \multicolumn{11}{|c|}{ Appraisal Set } \\
\hline \multirow{2}{*}{ S1 } & 0.216 & 0.343 & 0.512 & 0.729 & 1.000 & 1.000 & 1.000 & 1.000 & 1.000 & 1.000 & 1.000 \\
\hline & 0 & 0 & 0 & 0 & 0 & 0 & 0 & 0 & 0 & 0 & 0 \\
\hline \multirow{2}{*}{$\mathrm{S} 2$} & 0.064 & 0.125 & 0.216 & 0343 & 0.512 & 0.729 & 1.000 & 1.000 & 1.000 & 1.000 & 1.000 \\
\hline & 0 & 0 & 0 & 0 & 0 & 0 & 0 & 0 & 0 & 0 & 0 \\
\hline \multirow{2}{*}{$\mathrm{S} 3$} & 0.234 & 0.367 & 0.544 & 0.769 & 1.000 & 1.000 & 1.000 & 1.000 & 1.000 & 1.000 & 1.000 \\
\hline & 0 & 5 & 0 & 5 & 0 & 0 & 0 & 0 & 0 & 0 & 0 \\
\hline
\end{tabular}

The calculated values of the range of appraisal product value $(\alpha)$, the different of range of appraisal product value $\left(\Delta \alpha_{l}\right)$, and mean value of $E_{m \alpha},\left(H_{l}\left(E_{m \alpha}\right)\right)$ are tabulated in Table 12.

Table 12: Calculated Range of $\alpha, \Delta \alpha_{l}$, and $H_{l}\left(E_{m \alpha}\right)$

\begin{tabular}{|c|c|c|c|c|}
\hline$l$ & Range $\alpha$ & $E_{m \alpha}$ & $H_{l}\left(E_{m \alpha}\right)$ & $\Delta \alpha_{l}$ \\
\hline 1. & $\begin{array}{l}0.0000<\alpha \leq \\
0.2160\end{array}$ & $\begin{array}{l}\{0,0.1,0.2,0.3,0.4,0.5,0.6,0.7,0.8 \\
0.9,1\}\end{array}$ & 0.50 & 0.2160 \\
\hline 2. & $\begin{array}{l}0.2160<\alpha \leq \\
0.3430\end{array}$ & $\begin{array}{l}\{0.1,0.2,0.3,0.4,0.5,0.6,0.7,0.8 \\
0.9,1\}\end{array}$ & 0.55 & 0.1270 \\
\hline 3. & $\begin{array}{l}0.3430<\alpha \leq \\
0.5120\end{array}$ & $\{0.2,0.3,0.4,0.5,0.6,0.7,0.8,0.9,1\}$ & 0.60 & 0.1690 \\
\hline 4. & $\begin{array}{l}0.5120<\alpha \leq \\
0.7290\end{array}$ & $\{0.3,0.4,0.5,0.6,0.7,0.8,0.9,1\}$ & 0.65 & 0.2170 \\
\hline 5. & $\begin{array}{l}0.7290<\alpha \leq \\
1.0000\end{array}$ & $\{0.4,0.5,0.6,0.7,0.8,0.9,1\}$ & 0.70 & 0.2710 \\
\hline 6. & $\begin{array}{l}1.0000<\alpha \leq \\
1.0000\end{array}$ & $\{0.5,0.6,0.7,0.8,0.9,1\}$ & 0.75 & 0.0000 \\
\hline 7. & $\begin{array}{l}1.0000<\alpha \leq \\
1.0000\end{array}$ & $\{0.6,0.7,0.8,0.9,1\}$ & 0.80 & 0.0000 \\
\hline 8. & $\begin{array}{l}1.0000<\alpha \leq \\
1.0000\end{array}$ & $\{0.7,0.8,0.9,1\}$ & 0.85 & 0.0000 \\
\hline
\end{tabular}


The calculated values of the range of $\alpha, \Delta \alpha_{l}$, and $H_{l}\left(E_{m \alpha}\right)$ are substituted in the following Equation (7) to calculate the satisfaction value in the final step of the method.

$$
S V(m)=\frac{1}{\alpha_{\max }} \sum_{l=1}^{11} H_{l}\left(E_{m \alpha}\right) \Delta \alpha_{l}
$$

where $\alpha=$ degree of appraisal product value, $\Delta \alpha_{l}=\alpha_{l}-\alpha_{l-1}, \alpha_{0}=0, H_{l}\left(E_{m \alpha}\right)=$ midpoint $\mathrm{V}_{l}(l=1,2,3 \ldots, 11)$ and $\alpha \max =$ maximum degree of appraisal product value.

\section{NUMERICAL RESULT}

The results of evaluating the ranking of the best attack helicopters are tabulated in Table 13 . Columns 2, 4 and 3, 5 of Table 13 illustrate the performance value and ranking order for measuring weapon system of attack helicopters alternatives S1, S2, and S3 respectively. The satisfaction values calculated by using the fuzzy evaluation model represent the performance values which are used to rank the attack helicopters alternatives. The satisfaction values in column 4 were $0.5683,0.5947,0.5622$ and in column 5 the rankings were $2,1,3$ respectively. The Cheng et al. (1999) method produced the performance values and ranking as listed in columns 2 and 3 as $0.151,0.248,0.143$ and 2, 1, 3 respectively. Clearly, it shows that the satisfaction values are higher than the values obtained from Cheng et al.'s method. The higher value indicates that the reliable experts are satisfied with the attack helicopters alternatives offered. From these results, the fuzzy evaluation model shows outstanding performance when compared to Cheng et al.'s method with 100\% accuracy in ranking three attack helicopters alternatives, S1, S2, and S3. Again the subjective evaluation method showed the advantage of simpler rules properties with a smaller number of rules and at minimum length.

Table 13: Results of Attack Helicopters

\begin{tabular}{|c|c|c|c|c|}
\hline Method & \multicolumn{2}{|c|}{ Cheng et al. } & \multicolumn{2}{c|}{ Subjective evaluation } \\
\hline & Performance & Ranking & Performance & Ranking \\
\hline A & 0.151 & 2 & 0.5683 & 2 \\
B & 0.248 & 1 & 0.5947 & 1 \\
C & 0.143 & 3 & 0.5622 & 3 \\
& & & & $100 \%$ \\
\hline Acc \% & & & & \multicolumn{2}{c}{} \\
\hline
\end{tabular}




\section{CONCLUSION}

A new fuzzy evaluation model has been proposed for the evaluation of the attack helicopters. Experimental results produced are comparable to results obtained from the model by Cheng et al. The significance of the research model was the application of a fuzzy expert system consisting of a set of rules in the form of IF (antecedent) THEN (Conclusion). The model could be used as an alternative approach in solving problems that involve uncertainties. The evaluation output would become more precise if the combination factors were accurately defined. The rule properties were also analysed to judge the strength of the subjective evaluation method. The results of the experiments showed remarkable ranking performance even with the use of small-sized rule properties.

\section{References}

Biswas, R. (1995). An Application of Fuzzy Sets in Student's Evaluation, Fuzzy Set and Systems, 74: 187-194.

Cheng, C., Yang, K. and Hwang, C. (1999). Evaluating Attack Helicopters by AHP Based on Linguistic Variable Weight, European Journal of Operational Research, 116: 423-435.

Chou, T.Y and Liang, G.S., (2001). Application of a Fuzzy Multi-criteria Decision-making Model for Shipping Company Performance Evaluation, MARIT. POL. MGMT., 28(4): p. 375 $-392$.

Chu, F. (1995). Fuzzy Multicriteria Decision-Making in Distribution of Factories: An Application of Approximate Reasoning, Fuzzy Sets and Systems, 71: 197-205.

Hong, T.P. and Lee, C.Y. (1996). Induction of Fuzzy Rules and Membership Functions from Training Examples, Fuzzy Sets and Systems, 84: 33-47.

Klir, G. J. and Folger, T. A. (1988). Fuzzy Sets, Uncertainty, and Information, New York: Prentice-Hall International Inc.

Laarhoven and Pedrycz (1983). A Fuzzy Extension of Saaty's Priorty Theory, Fuzzy Sets and Systems, 11: 229-241.

Lee, K.M., Cho, C.H., and Kwang, H.L. (1994). Ranking Fuzzy Values with Satisfaction Function, Fuzzy Sets and Systems, 64: 295-309.

Li, H.C. and Ilacqua, J.A. (1994). Job Search and Employment, Fuzzy Sets and Systems, 68: 335-342.

Liang, G. and Wang, A. (1992). Personnel Placement in a Fuzzy Environment, Computers Operations Research, 19(2): 107-121.

Mon, D.L., Cheng, C.H. and Lin, J.C. (1994). Evaluation Weapon System Using Fuzzy Analytical Hierarchy Process Based on Entropy Weight, Fuzzy Sets and Systems, 62: 27-134.

Othman, M., Ku-Mahamud, K.R. and Bakar, A.A. (2003). Quality Evaluation Using Two Phase Fuzzy Approach, Proceeding DSI 7TH International Conference, Shanghai, China.

Othman, M., Ku-Mahamud, K.R. and Bakar, A.A. (2004a). Fuzzy Rule Generation Using Membership Function, Proceeding The 4th Information and Computer Engineering Postgraduate Workshop, Phuket Thailand, p. 115 - 120.

Othman, M., Ku-Mahamud, K.R. and Bakar, A.A. (2004b). Fuzzy Similarity Function For Ranking River Basin Planning Alternatives, Preprints Fifth International Workshop on Artificial Intelligence in Agricultural, Cairo, Egpyt, p. 95 - 100.

Othman, M., Ku-Mahamud, K.R. and Bakar, A.A. (2004c). Ranking The River Basin Planning Alternatives Using Fuzzy Approximate Reasoning, Chiang Mai Journal of Science.

Othman, M., Ku-Mahamud, K.R. and Bakar, A.A. (2004d). Subjective Evaluation Using Fuzzy Rule Approach, Journal of Institute of Mathematics \& Computer Sciences (Comp. Sc. Series), 15(1).

Pedrycz,W. and Gomide F. (1998). An Introduction to Fuzzy Sets Analysis and Design, England: The MIT Press.

Saaty, T.L. (1995). The Analytic Hierarchy Process, Pittsburgh: RWS Publications. 
Sonja P. L. (2001). Personnel Selection Fuzzy Model, International Transactions in Operational Research, 8(1): 89-105.

Turban, E., Zhou, D. and Ma, J. (2000), A Methodology for Grades of Journals: A Fuzzy SetBased Group Decision Support System, Proceedings of the 33rd Hawaii International Conference on System Science.

Turksen, I.B. (1992). Fuzzy Expert Systems for IE/OR/MS, Fuzzy Sets and Systems, 51:1-27. Turksen, I.B. and Wilson, I.A. (1994). A Fuzzy Sets Preference Model for Consumer Choice, Fuzzy Sets and Systems, 68: 253-266.

Weon, S. and Kim, J. (2001). Learning Achievement Evaluation Strategy Using Fuzzy Membership Function, ASEE/IEEE Frontiers in Education Conference, pp. 19-24.

Yamasita, T. (1997). On a Support System for Human Decision Making By the Combination of Fuzzy Reasoning and Fuzzy Structural Modeling, Fuzzy sets and Systems, 87: 257-263. 